\title{
Research on International New Industry Cooperation in the Core Area of Maritime Silk Road
}

\author{
LINGLAN FU, J. L. SU* \\ School of Business, Quanzhou institute of information engineering, 362000, Quanzhou, China \\ TSL School of Business, Quanzhou Normal University, 362000, Quanzhou, P. R. China*
}

\begin{abstract}
This paper analyzes the main problems and difficulties faced by private enterprises in upgrading and upgrading in our province and explores the countermeasures for effectively accelerating the transformation and upgrading of private enterprises through several field investigations inside and outside the province. Through several provincial surveys and cross-provincial studies, the research group visited several typical private economic regions and their successful enterprises, explored their successful development experience and regional policy advantages, and put forward some countermeasures to accelerate the transformation and upgrading of private enterprises. Through investigation, the research group found that private enterprises in our province are facing problems in the new normal of economic development on private enterprises many impact; Through in-depth analysis and research, the research group puts forward the corresponding countermeasures, that is, accelerate the supply-side structural reform, and strive to provide beneficial policy advice and Suggestions for accelerating the transformation and upgrading of private enterprises in our province.This paper focuses on the research on international new industry cooperation in the core area of maritime silk road. FuJian is facing the main problems and difficulties in the international new industry cooperation. After thorough investigation and analysis, the research group put forward several feasible schemes.
\end{abstract}

\section{Introduction}

After more than a decade of cooperative development since the national maritime silk road development strategy was put forward, China and countries along the silk road have a sound political foundation and a strong economic foundation. The 21st century maritime silk road strategy meets the common interests and common requirements of China and asean countries. After years of development, FuJian's three leading industries of electronics, machinery and petrochemicals, as well as light industry, textile, building materials and food, have certain industrial advantages in China, and have a good foundation for going global to carry out international production capacity cooperation. At the same time, FuJian's economic and social development still has a large demand for agricultural products, energy and mineral resources. Therefore, in terms of international production capacity cooperation, m\&a investment in foreign resource products is also needed. At present, the strength of international new industry cooperation in the core area of FuJian maritime silk road still needs to be further improved. There are differences between FuJian and the silk road countries in terms of industry cognition and cooperation needs, differences in the financial system system along the "maritime silk road", and insufficient promotion and publicity of FuJian's foreign cultural exchanges.

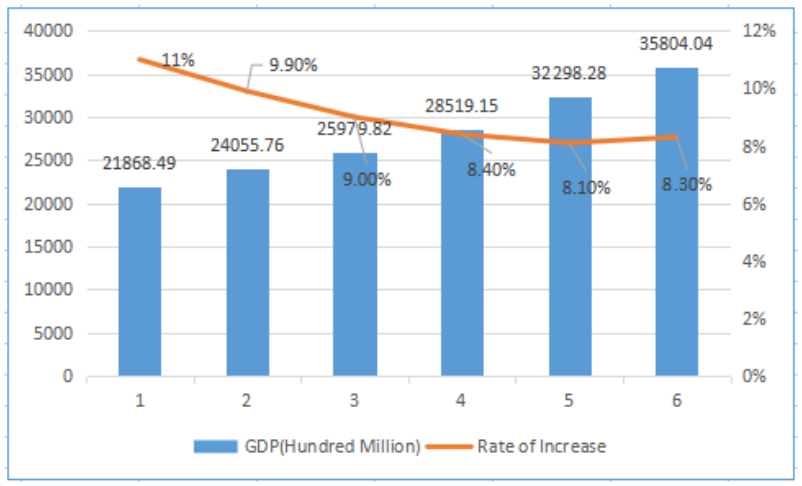

Figure 1. Total GDP of FuJian province and its growth rate from 2013 to 2018

(The data are from the China Business Industry Research Institute database)

Research for the analysis of the private enterprises in our province to upgrade transformation in main problems and difficulties, to explore the effective countermeasures to promote the transformation and upgrading of private enterprises in our province, the team organized many times of both field investigation, the sections of private economic regions, including jiangsu, zhejiang and other more held in-depth field research, many times with the

su_jinlong@hotmail.com* 
local relevant government department and enterprise representatives, visited a number of successful transformation of private enterprises, the field survey obtained first-hand information for the development of private economy.

Private enterprise holds the balance in FuJian economy position. After years of development, private enterprises in FuJian have undergone great changes in their management system and operating mechanism, which have greatly improved their vitality and competitiveness. Under the new normal, there are still many institutional, institutional, structural and historical problems that private enterprises need to further solve and they are becoming increasingly difficult. In the macro environment where the new round of scientific and technological revolution and the transformation and upgrading of China's manufacturing industry form a historic intersection, FuJian, as one of the most active regions for private enterprises in China, must seize the historical opportunity, give full play to its advantages, transform and upgrade in an all-round way, and stride into the ranks of the strong manufacturing provinces in China. In 2018, the GDP of FuJian reached 3,580.404 billion yuan, an increase of 8.3 percent or 0.2 percentage points over the previous year in comparable prices. By sector, the added value of the primary industry was 237.982 billion yuan, up 3.5\%; The added value of the secondary industry was 1723.236 billion yuan, up $8.5 \%$; The added value of the tertiary industry was 1619.186 billion yuan, up $8.8 \%$.

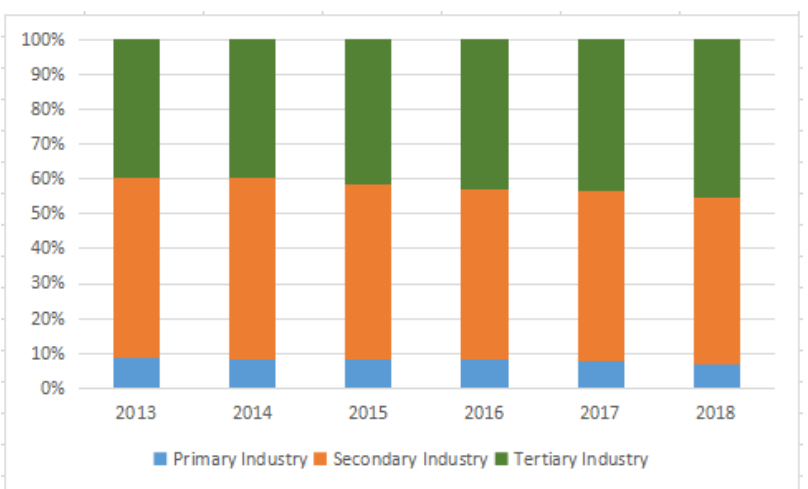

Figure 2. The proportion of added value of the three industries in GDP of FuJian province from 2013 to 2018

(The data are from the China Business Industry Research Institute database)

In 2018, the added value of industries above the designated size in the province increased by 9.1 percent or 1.1 percentage points over the previous year. The value added of light industry increased by 8.9 percent and heavy industry by 9.2 percent. By type of registration, the added value of state-owned enterprises increased by 7.8 percent, joint-stock enterprises by 10.3 percent, joint-stock cooperative enterprises by 14.4 percent, and enterprises with foreign investment and investment from Hong Kong, Macao and Taiwan by 6.9 percent. The value added of the mining sector grew by 7.8 percent, the manufacturing sector by 8.9 percent, and the power, heat, gas and water production and supply sectors by 11.9 percent. However, under the background of the us-china trade war, our province is faced with the new normal of intensified market competition, traditional overcapacity, strengthened resource and environmental constraints, and rising cost of factors, the development of our manufacturing industry is also faced with severe challenges, and the transformation and upgrading is urgent.

The number of small and medium-sized enterprises in China accounts for more than $99 \%$ of the total number of enterprises in the country. They are the fresh force of China's economic development and play an important role in promoting economic growth, relieving employment pressure and maintaining social stability. FuJian province, especially FuJian minnan area, is one of the most active places for the development of private enterprises in China. In the past 40 years since the reform and opening up, the number and scale of private enterprises in FuJian have been growing rapidly year by year. Private enterprises have become one of the main driving forces for the economic development of FuJian, especially in southern FuJian.

In 2018 , the ex-factory price of industrial producers in the province rose 2.8 percent, or 1.3 percentage points less than that of the previous year. December was up $2.4 \%$ from a year earlier and down $0.6 \%$ from a month earlier. In 2018 , the purchase prices of industrial producers rose 2.8 percent year-on-year, or 2.5 percentage points less than the previous year. December was up $1.2 \%$ from a year earlier and down $1.0 \%$ from a month earlier.

However, due to many natural defects of private enterprises in capital strength, development strategy, management and technology upgrading, market expansion, etc., the abnormal death and shortened survival period of private enterprises has become a new normal in the development process of China's private economy. In recent years, China's economic development and growth mode will have a major change in the macro background, private enterprises in the low industrial quality is a private enterprise in the process of development is more prominent and urgent to solve the problem. Especially in the context of the new one road and one belt policy, FuJian, as the core area of the maritime silk road, faces a lot of problems to be solved urgently.

The research is supported by the achievements of some projects, such as the "Research on the block chain technology management innovation of emergency resource supply chain" (FJ2020B045) and which is a Fujian Social Science Planning Project, the "A special study on the system of River and lake chiefs in Yongchun County" (2020H25) which is Quanzhou Social Science Planning Project.

This paper, which lays emphasis upon the current situation of Economic development in FuJian, and how to speed up international cooperation in new industries in the core area of maritime silk road in FuJian province. The overall organization of the paper is as follows. After the introduction, in Section II we present the current situation of Economic development in FuJian, and it lists a lot of data and charts. The main problems and difficulties in the international new industry cooperation in the core area of maritime silk road are clarified in section III, including severe overcapacity in some industries, overstock of real estate, poor international export environment and high 
corporate debt. In section IV, the research group suggested that the government take some measures to accelerate the international cooperation of new industries in the core areas of the maritime silk road, are touched upon. Finally, Section V concludes the paper.

\section{FuJian is Facing the Main Problems and Difficulties in the International New Industry Cooperation}

Firstly, the strength of FuJian's international industrial cooperation needs to be further enhanced. FuJian has just started to make foreign investment and carry out international cooperation on production capacity. In general, FuJian enterprises still have a short version of foreign investment, and the foundation for international cooperation on production capacity is not solid and the preliminary preparations are not sufficient. Therefore, to promote international cooperation on production capacity, we need to lay a solid foundation for it and build up internal strength.

Secondly, FuJian and silk road countries share the same cognition and cooperation needs. Silk road in the Chinese history is a part, but for countries along, many countries of the historical origin and no special memories and emotions, so how to carry forward the Chinese culture to the country, along with China along the silk road to respect and recognition, real through the silk road will be emotional, cognitive and seeking common ground while putting aside differences across countries, gradually appreciate each other, establish a diversified value view and cultural view, still need to gradually explore in practice.

Thirdly, differences in financial systems along the maritime silk road. In the financial system, strengthening mutual trust and cooperation, support the development of the bilateral mature bank develops the network in the territory, actively promote the stability of the silk road economic belt the monetary system, and establish the credit system and finance system, in terms of regional cooperation system, establish effective communication and coordination mechanism, to provide efficient and so on to the trade dispute solution solving mechanism.

Fourthly, the promotion and publicity of FuJian's foreign cultural exchanges are still insufficient. As the countries along the maritime silk road are complex areas of international geopolitics and economic development, this complex environment will more or less bring resistance to the spread of FuJian-featured culture. Judging from the current spread and promotion of FuJianfeatured culture in the countries along the maritime silk road, there are still some restricting factors, and it is difficult to form a cultural synergic resonance effect and play a strong supporting role in the promotion of the maritime silk road strategy. Through more cultural exchanges, China and countries along the belt and road can have more in-depth understanding of other countries' systems and culture. After the citizens' overall cognition of culture and system is improved, the contradiction associated with education and system will be alleviated.

\section{Suggestions on accelerating international cooperation on new industries in the core area of the maritime silk road}

Firstly, we need to enhance our strength through industrial cooperation on the silk road.

Promote industrial upgrading and promote industrial cooperation along the maritime silk road. The industrial upgrading plan of maritime silk road pilot zone policy can inject strong impetus into FuJian's economy. We will give full play to the brand effect of the Taiwan investment zone, the economic and technological development zone, and the high-tech industry development zone, and take advantage of the industrial cooperation policies of the maritime silk road and the policies of the FuJian free trade zone to focus on the development of high-tech industries and modern producer services. Strengthen the guidance of industrial planning, strengthen the overall coordination of the major industrial parks in the huanwan region, further clarify the functional positioning of the major industrial parks, promote the centralized and intensive development of enterprises into professional parks, and create innovative transformation demonstration zones.

Take advantage of the maritime silk road policy to integrate the development of industries, ports and cities. Strengthen the planning and layout of FuJian lingang new district, aim at higher standards, and accelerate the large-scale and characteristic development of industrial parks. Promote the development of production harbour city fusion, can use "Marine silk road", develop the Marine economy, relying on the construction of China's ocean property rights trading center, the maritime silk route Marine engineering equipment manufacturing base, repairing yard Marine engineering equipment projects, Taiwanese investment zone and Taiwan yacht base project of leading role, can effectively promote petrochemical, Marine engineering equipment, new energy, stone, port logistics, Marine biological medicine such as strategic port-vicinity industry.

Rejuvenate the ancient customs of the maritime silk road and promote international tourism industry cooperation. Quanzhou of FuJian province is the ancient "largest port in the east". In the revival plan, shishi xiangzhi fishing port style town, jinjiang shenhu fisherman's wharf leisure tourism project, huian chongwu national Ocean Park and other projects are concentrated in operation to generate a batch of characteristic port tourism mainly focusing on the investigation of maritime silk road relics. The artificial island berth of xiutu in the construction is planned and adjusted to adapt to the development trend of international cruise ships, and the routes of Taiwan peng jinma, southeast Asia, Africa and Europe are opened up to reproduce the ancient port of the starting point of the maritime silk road. Replacement after the transformation of the ancient port of erythrina subject area - in zhu Hong Kong to Taiwan, the golden gate and yacht special port area of the existed passenger wharf, perfect the leisure entertainment, duty-free shopping and sightseeing holiday supporting service 
functions, such as introduction of upstream and downstream industries, and build the yacht industry cluster as the core of the modern waterfront city center, promote the ancient port city taste and external image. It is suggested that we should continue to build new forms of business matching the elements of the maritime silk road, vigorously develop high-end services such as cultural tourism, enhance the ability of innovation and agglomeration in the central city, and constantly improve the driving force.

Secondly, we need to promote win-win development of the silk road countries through international industrial cooperation.

Focus on optimizing industrial structure and strengthening the driving effect of foreign cooperation projects. FuJian in involved in the process of "area" strategy, to optimize the investment structure, through the economic cooperation of large projects to promote the development of large, and through the big projects demonstration effect of comprehensive cooperation of driving all the way "area" strategy, on the basis of constantly sum up experience steadily push forward the economic cooperation projects, capital investment to use in making overall increase the amount of investment, structure and benefits. Vigorously explore FuJian's economic advantages, on the basis of detailed scientific research and through successful cooperation in largescale projects, win more national "One Belt And One Road" construction fund support, let FuJian more involved in "One Belt And One Road" strategy.

Encourage outstanding enterprises to participate in international competition and promote industrial upgrading and adjustment. Select competitive enterprises for key support, build a batch of multinational enterprises with international competitiveness, create a batch of excellent FuJian enterprises with international brand effect, encourage excellent enterprises to participate in the construction of "One Belt And One Road" project, give play to brand effect, and actively participate in international competition.

Strengthen cooperation in infrastructure construction and ensure unimpeded trade. FuJian unicom in facilities, can according to the actual situation, cooperation areas using ancient port advantage as countries along the silk road was built a batch of important trade channels, rebuild the reputation of the ancient "Oriental first port", build a bridge of trade to long-term and stable cooperation, to help China slowly form a connection between the Asian area and the non infrastructure network.

Thirdly, we need to promote financial cooperation along the silk road

Actively seek support from aiib and the silk road fund. As the pilot zone, FuJian should actively seek financial support from aiib for major infrastructure projects such as ports and railways, so as to lay a solid foundation for the construction of the core area of the maritime silk road. In addition, FuJian can try to establish a special fund under the "silk road fund" to attract private and overseas capital to participate in the construction of the pilot zone, and give key support to the development of foreign economic and trade business, which is conducive to expanding and strengthening the economy of FuJian.

Guiding overseas Chinese industries along the maritime silk road to invest in cooperation. Attracting overseas Chinese to invest in FuJian's economic construction and share the dividend of the development of the motherland will not only bring win-win cooperation, but also enable overseas Chinese to find the root of "home" and the spiritual home of homesickness. More than 15.8 million overseas Chinese are from FuJian, $90 \%$ of whom live in southeast Asia and other countries along the maritime silk road. In addition to the large number of overseas Chinese, many overseas Chinese of FuJian nationality have strong economic strength and extensive social influence. They have been active in the economic and social activities along the maritime silk road, playing an important role in promoting the economic and trade cooperation and cultural exchanges between FuJian and countries along the maritime silk road. At the same time, the overseas Chinese in FuJian have always had the fine tradition of donating money for education, investment and business development, etc., to guide the overseas Chinese to return to investment, which not only has emotional basis, but also can share the real needs of the development dividend of the motherland.

Promoting cross-border private financing along the maritime silk road. We should make full use of nongovernmental financial support from countries along the maritime silk road, attract foreign capital, strengthen cooperation between government, Banks and enterprises, give full play to the role of financing platforms, leverage social capital of countries along the maritime silk road, and enlarge the effect of capital scale. Give full play to the advantages of the famous hometown of overseas Chinese and FuJian securities market, and actively guide overseas Chinese, local talents and listed enterprises to support the economic development of FuJian with funds. We will further explore the establishment of a diversified and sustainable fund guarantee mechanism, explore cooperation with overseas private capital, and adopt PPP and other financing models to contribute to the economic construction of FuJian.

Fourthly, promote cooperation in the silk road industry through cultural exchanges.

Promoting non-governmental commercial cooperation among countries along the silk road. Borrows the Marine silk road area in policy of trade flow gripper, deepen the important carrier of economic and trade exchanges, such as China (FuJian) maritime silk road international brand exhibition, maritime silk LuFuJian commodities fair, etc., relying on the historical origin and the complementary advantages of production factors, helping enterprises to expand marketing channels along the silk road, expand two-way trade and investment, promoting national folk economic and trade exchanges and cooperation.

Strengthen international cultural cooperation. We will strengthen people-to-people exchanges, promote peopleto-people exchanges with southeast Asia and other countries and regions along the maritime silk road, and enhance understanding and friendship between cities and people. For some history and culture, the ancestral hall, 
folk houses, buildings, families through the whole village protection, and local protection into protection, such as the ancient luoyang bridge area of the ancient city of quanzhou, shishi yongning (ancient city) history culture and the coastal projects, abundant state city, chongwu ancient city cultural heritage protection project head of historical and cultural town, anxi lake tourist area, series of $\mathrm{Hu}$ mountain ancient town tourism projects, dehua Chinese ancient ceramic culture and so on the maritime silk route heritage sites, as far as possible to give original repair, preserved, let people remember homesickness, to retain memory, let the historical context to get the pass, Let the ancient city of the maritime silk road become the common spiritual home of the silk road countries.

Continue to deepen the industrial cooperation between FuJian and Taiwan. FuJian should actively support taiwan-funded enterprises to accelerate local transformation in deepening the industrial cooperation between FuJian and Taiwan. Development strategy of the advanced manufacturing industry in FuJian as the guidance, accelerate the FuJian and Taiwan enterprises in the industrial chain of high-end and key links of cooperation, in particular to strengthen on both sides of the enterprises in the technical cooperation with industry standards, through the complementary advantages of geographic cluster effectively into industry cluster advantages, attract more capital and Taiwan enterprises in FuJian..

\section{Conclusion}

In this paper, research on international new industry cooperation in the core area of maritime silk road was presented. Specifically, the current situation of Economic development in FuJian was introduced. In addition, the impact of the new normal of economic development on private enterprises. At present, FuJian international industrial cooperation strength is yet to be further enhance, the silk road, national industrial differences in cognitive and cooperation, "Marine silk road" of the financial system along differences, FuJian foreign cultural exchanges to promote and insufficient propaganda are still many problems, such as are obstacles in FuJian area play the proper role in all the way. Team after in-depth research and analysis on the problem put forward several measures, including: borrow "silk road" industry cooperation to improve its strength, drive "silk road" countries by international industrial cooperation and winwin development, promote the "silk road" the financial sector cooperation, such as promoting cultural exchanges between the "silk road" industrial co-operation corresponding solutions.

We firmly believe that as the core area of the maritime silk road, FuJian will play a leading, exemplary, gathering and radiating role in connectivity, economic and trade cooperation, institutional innovation, cultural and people-to-people exchanges, and give full play to the geographical location, popularity, history, culture, opening-up and industrial development of various regions of FuJian.

\section{References}

1. Cui M, Pan S L, Newell S, et al. Strategy, Resource Orchestration and Ecommerce Enabled Social Innovation in Rural China[J]. Journal of Strategic Information Systems, 2016,26(1):3-21.

2. Avgerou $\mathrm{C}, \mathrm{Li}$ B. Relational and Institutional Embeddedness of Web-Enabled Entrepreneurial Networks: Case Studies of Netrepreneurs in China[J]. Information Systems Journal.2013,23(4):329-350.

3. Bailey A, Ngwenyama O. Toward Entrepreneurial Behavior in Underserved Communities: An Ethnographic Decision Tree

Model of Telecenter Usage $[\mathrm{J}]$. Information Technology for Development. 2013,19(3):230-248.

4. Bathelt H, Boggs J S. Toward a Reconceptualization of Regional Development Paths: Is Leipzig's Media Cluster a Continuation of or a Rupture with the Past Economic Geography. 2010;79(3):265-293.

5. Bosworth G, Atterton J. Entrepreneurial Inmigration and Neoendogenous Rural Development[J]. Rural Sociology, 2012,77(2):254-279.

6. Gao B, Chan W K, Chi L, Deng X. Size and Growth Dynamics of Online Stores: A Case of China's Taobao.com[J] Electronic Commerce Research and Applications. 2016,17:161-72.

7. Li R,Wang Q, Cheong K C. From Obscurity to Globa Prominence-

Yiwu's Emergence as an International Trade Hub[J] Cities. 2016

8. Liu C, Li J, Liu J. Rural E-Commerce and New Rural Business Model: A Case Study Of "Taobao Village" In Jiangsu Province[J]. Asian Agricultural Research. 2015,7(11):35-37,46.

9. Long H, Liu Y. A Brief Background to Rural Restructurin $\mathrm{g}$ in China: A Forthcoming Special Issue of Journal of Rural Studies[J]. Journal of Geographical Sciences.2015， 25(10):1279-1280.

10. Overby E, Forman C. The Effect of Electronic Commerce

Geographic Purchasing Patterns and Price D ispersion[J]. Informs. 2015,61(2): 431-453.

11. Salemink K, Strijker D, Bosworth G. Rural Development in the Digital Age: A Systematic Literature Review on Unequal ICT Availability, Adoption, and Use in Rural Areas[J]. Journal of Rural Studies. 2015, 54:360-371.

12. Sandeep M S, Ravishankar M N. Social Innovations in Outsourcing: An Empirical Investigation of Impact Sourcing Companies in India[J]. Journal of Strategic Information Systems. 2015,24(4):270-288.

13. Yeung H W C, Coe N. Toward A Dynamic Theory of Global Production Networks[J] Economic Geography. 2015,91(1):29-58. 